\title{
Espacios alternativos de formación en la construcción de culturas políticas: una propuesta para su análisis*
}

\author{
Amelia Molina García**
}

\section{Resumen}

Este artículo presenta algunas reflexiones sobre los conceptos que se han generado a partir del estudio de la juventud y la acción política, producto de la investigación denominada "Indicadores y procesos en la conformación de la cultura política juvenil" (Molina 2004, 2008 y 2012; Molina y Ponce, 2011). En particular, con los jóvenes que participan como Instructores Comunitarios (IC) del Consejo Nacional de Fomento Educativo (CONAFE). Se busca enfocar la mirada hacia los jóvenes partícipes de experiencias en la conformación de identidades y de cultura política -como signo distintivo de la construcción de identidades proyecto. Para ello, se presenta un estado de la cuestión sobre la temática en el contexto mexicano, para después desarrollar un acercamiento conceptual sobre las esferas de poder como referente analítico y la noción de constelaciones, como herramienta metodológica para el análisis de los procesos de conformación de culturas políticas e identitarias en jóvenes menores de dieciocho años.

\footnotetext{
* Artículo recibido el 20 de Mayo de 2015. Aceptado el 15 de Julio de 2015.

** Amelia Molina García es Maestra en Investigación y Desarrollo de la Educación. Universidad Iberoamericana. Licenciada en Pedagogía por la UNAM (México), Especialista en Planeación, Investigación y Administración Educativa por el Instituto Nacional de Administración Pública (INAP), y Diplomada en Encuestas, Diseño y Realización, por la UAM.

Correo electrónico: meluxmolina@hotmail.com
} 


\section{Palabras clave}

Cultura política - ciudadanía juvenil - espacios alternativos de formación.

\section{Abstract}

This article presents a reflection on the concepts that have been generated from the study of youth and political action, research product called "indicators and processes in shaping young people's political culture" (Molina 2004, 2008 and 2012; Molina $\&$ Ponce, 2011). Specifically with youth involved as community instructors (IC) of the National Council for Educational Development (CONAFE). It seeks to focus on the young participants whose experiences in shaping their identities and political culture, is a distinctive sign in the construction of an identity-project. For this purpose, I am presenting a state of affairs on this issue in the Mexican context, followed by a conceptual approach on areas such as analytical reference power and the notion of constellations as a methodological tool for the analysis of the processes of formation of political cultures and identity in young people under eighteen years of age.

\section{Keywords}

Political Culture - youth citizenship - Alternative Training Spaces

\section{Introducción}

Los jóvenes y la cultura política constituyen los componentes esenciales en la construcción de una propuesta para el análisis de este objeto de estudio. Por ello, primero se presenta un estado general de la cuestión, que da cuenta de algunos elementos y reflexiones que la han caracterizado. Considerando tal revisión, se busca superar la forma tradicional de abordar este campo temático, el cual ha sido visto como expresión de la participación electoral o simplemente como las percepciones que se obtienen de los sondeos para conocer lo que piensan los sujetos involucrados respecto a figuras o momentos políticos y no como la experiencia social (trayectoria formativa) que lleva a los individuos a tener determinadas perspectivas o prácticas en la conformación de su cultura política. En la parte inicial del artículo se analiza cómo los jóvenes han sido foco de atención de diversos organismos estatales y cuáles han sido las definiciones y los referentes conceptuales mediante los que se les ha caracterizado. Asimismo, se abordan dos ejes temáticos: uno sobre nociones de juventud y el otro respecto a cómo ha sido concebida la cultura política. 
Posteriormente, derivada de las revisiones y reflexiones analíticas, se presenta la postura teórico-conceptual que se asume en la construcción del objeto de estudio, dando pie a la noción de constelaciones, como propuesta para la construcción de una herramienta analítica, basada en las esferas de poder y la tensión que se genera entre el desarrollo de la autonomía y la nautonomía (Held, 1998), lo que por cuestiones de espacio, solo nos limitaremos a esbozar algunas conclusiones relacionadas con la posibilidad de utilizar esta propuesta como andamiaje conceptual y metodológico en la construcción de un modelo de análisis sobre cultura política, con el objetivo de cultivar nuevas reflexiones sobre los jóvenes en general.

\section{Aproximación a las nociones de joven, juventudes y lo juvenil Las instituciones orientadas hacia la juventud}

La temática juvenil en México remonta sus antecedentes al año 1938, con la instauración de la llamada Confederación de Jóvenes Mexicanos. ${ }^{1}$ No obstante, institucionalmente, con la creación de la Oficina de Acción Juvenil dentro de la Secretaría de Educación Pública (SEP), en 1942, esta secretaría se ha encargado de dirigir diversas políticas que orientan formas de atención y de ocupación para los jóvenes. Las acciones y políticas han variado de acuerdo a las prioridades nacionales, así como por la detección de necesidades juveniles. Condición que ha llevado a la creación de diversas instancias para la atención a la juventud, tales como: el Instituto Nacional de Juventud (INJUVE); el Consejo Nacional de Recursos para la Atención de la Juventud (CREA); la Dirección General de Atención a la Juventud de la Comisión Nacional del Deporte (CONADE) y Causa Joven.

En la actualidad, el Instituto Mexicano de la Juventud (IMJUVE) se encarga de diseñar, instrumentar y evaluar políticas públicas que pretenden contemplar la diversidad juvenil mediante acciones de carácter normativo. Es importante señalar que desde finales de la década de 90, esta institución se ocupó, intensamente, de diversas líneas de investigación con las que se profundizó en el conocimiento de la población juvenil. Con tal propósito, además de apoyar el desarrollo y la publicación de estudios particulares sobre juventud, se generaron también estrategias de atención a este sector de la población, aunque de acuerdo con algunos críticos, estas instituciones tienen una visión homogénea sobre la juventud.

\section{Las orientaciones en los recortes sobre el estudio de la juventud}

Los ejes temáticos para analizar los procesos de intervención de la juventud en las esferas sociales incluyen aquellos que se refieren al análisis de los discursos que han producido conocimiento sobre los jóvenes, las culturas juveniles $y$, de manera particular, desde las perspectivas y desafíos que representa este campo, en especial considerando los procesos de descapitalización, desafiliación institucional e incertidumbres juveniles (Reguillo, 2000 y 2010).

En la revisión de algunos estudios se ha encontrado que los jóvenes no representan una cultura unívoca. La juventud es una categoría construida culturalmente y por ende, en la dimensión social, las transformaciones o cambios juveniles están vinculados necesariamente con

\footnotetext{
${ }^{1}$ Derivada de la conjunción de la Confederación de Estudiantes Socialistas de México y las Juventudes Socialistas, creando primero Las Juventudes Socialistas Unificadas de México. Cabe aclarar que si tuviésemos como intención relacionar el estudio de la juventud con los movimientos estudiantiles, habría que remontarse a las protestas realizadas en 1884 o a las organizaciones de jóvenes estudiantes en el periodo postrevolucionario -1920-, (Gómez Nashiki, 2003), pero no es nuestra intención en este espacio.
} 
los contextos socio-histórico-culturales y, de acuerdo con ciertas perspectivas críticas, pueden ser vistos como producto de las relaciones de fuerza en una determinada sociedad.

\section{Nociones y significados acerca de la juventud}

La noción de juventud ha sido abordada desde diversas perspectivas y concepciones, tanto tradicionales (funcionalistas, estructuralistas) como desde enfoques integrales y progresistas (crítica, socio-cultural). Estas nociones de significado han jugado un papel determinante en la construcción de sentidos, significaciones, valores y afirmaciones que ha desarrollado el mundo académico sobre la juventud (Cfr.: Alpizar y Bernal, 2003). Lo que puede ser explicado en función de un conjunto de aproximaciones teóricas que intentan, desde distintas disciplinas y momentos históricos y sociales, mirar y re-mirar a la juventud como una categoría de análisis y un fenómeno social que, como menciona Reguillo (2000 y 2010), es necesario construir y reconstruir a partir de un contexto sociohistórico específico, considerando la dimensión subjetiva de los jóvenes.

Con base en tales tendencias, se pueden identificar cinco aproximaciones teóricas sobre el estudio y la noción de la juventud, estas son: 1) como transición, 2) como integración social, 3) como agente de cambio, 4) como grupo generacional y 5) como praxis diferenciada.

\section{La juventud desde una concepción de transición}

Una primera aproximación teórica sobre la forma de mirar a la juventud, parte de la moratoria psicosocial $^{2}$ de Erik Erikson, la cual es vista desde un plano meramente psico-biológico, es decir, la juventud se mira como un estadio de la vida, como etapa de crisis y presencia común de patologías. Los jóvenes viven en una etapa de crisis que se refleja en la búsqueda de identidad.

Esta perspectiva puede ubicarse dentro de los enfoques más tradicionales o clásicos, porque su enfoque es en función de una etapa de la vida o, más bien, como una etapa de preparación de los individuos para ingresar al mundo adulto. Estas concepciones restan importancia al proceso de construcción de la juventud, pues, al parecer, solo es cuestión de tiempo para que se dé el tránsito entre la etapa de la niñez a la del ser adulto, obviando el complejo proceso de construcción y definición de identidad del mundo juvenil.

\section{La juventud como integración social}

La propuesta de corte estructuralista supone concebir a la juventud como un status, el cual se adquiere a través de la adecuación -o adaptación- de los individuos a determinadas actividades socialmente definidas. Desde esta perspectiva, los jóvenes deben ajustarse a las estructuras de actividad y procurar resolver las contradicciones emergentes entre las posibilidades y restricciones.

El estructural-funcionalismo combinado con el modelo de 'grupo etario' genera enfoques y concepciones de 'juventud' a partir de las nociones de trasgresión, en donde los jóvenes quebrantan, violan o evaden las normas y reglas de las relaciones sociales determinadas por los adultos, y de normalización o formas de integración del joven al orden normativo y de

\footnotetext{
${ }^{2}$ La moratoria social se refiere al alargamiento del periodo de la vida en que se es joven. Ahora, -afirma Erikson- los periodos de tiempo son más grandes, ya que los chicos se toman su tiempo para construir su identidad, para confrontarse con lo que quieren ser, para encontrar su lugar en el mundo (1986: 18).
} 
tipificación de comportamientos relacionados con lo juvenil. Esto presupone generalizar la noción de juventud como un modo de ordenar comportamientos y cuestiones simbólicas y de significación dirigidas a la preservación del orden social (Parsons, 1984).

\section{La juventud como agente de cambio}

A pesar de que en la segunda mitad del siglo XX la noción de juventud como grupo era vista más en su función etaria, principalmente desde un punto de vista poblacional, donde los jóvenes se convertían en un grupo homogéneo integrado por todas las personas que coinciden en un grupo de edad, es en los años sesenta y más propiamente en los noventa donde comienza a surgir una nueva noción o concepción de juventud, ya no simplemente como un grupo etario, homogéneo, transicional, o como factor de integración social, sino como agente con posibilidad de construir cambios sociales.

Entre estas aportaciones están las de Ronald Inglehart (1997), quien representa a esta nueva ola que entiende a los jóvenes en función de nuevos valores, en el contexto de las sociedades posmodernas. También es posible analizar a la juventud a la luz de las nuevas dinámicas sociales que permiten explicar lo social a partir de un paradigma estético, al que Maffesoli (1990) Ilama neotribalismo.

Este concepto permite comprender cómo las personas construyen nuevas formas de estar juntos, identificándose a partir de múltiples estilos de vida. Se da por supuesto que, así como las masas se hallan en perpetua ebullición, las tribus que se cristalizan en ellas no son estables y que las personas que componen estas tribus pueden moverse entre una y otra (Maffesoli, 1990). Estas formas emergentes de sociabilidad se pueden identificar en la juventud a través del neotribalismo como rasgo esencial de las culturas juveniles, en el que se plasman las transformaciones de la sociedad contemporánea, donde los jóvenes se congregan a partir de estilos de vida y prácticas diferenciadas y cambiantes, pero también transitorias.

En la misma perspectiva, encontramos con Martín-Barbero otra noción de juventud, cuya base conceptual está situada en la revisión de una nueva forma de estar juntos. La ruptura generacional y las nuevas formas de circulación del saber son los elementos centrales en esta concepción, mediante la que se permite explicar nuevas formas de ser de la juventud actual. La ruptura generacional, asociada a la cultura prefigurativa, se constituye como una experiencia de la realidad que se edifica en torno a los pares, cuyos referentes no están en el pasado, pero tampoco en el futuro. Los jóvenes de hoy han emigrado en el tiempo. Su vivencia está asociada a la posmodernidad, caracterizada por la fugacidad, la aceleración, la pérdida de certezas y el cambio. Con estos nuevos sentidos y formas de relación se está habitando un nuevo espacio comunicacional, en el que cuentan menos los encuentros (físicos y personales) y las muchedumbres pasean de manera virtual, en el tráfico, las conexiones, los flujos y las redes de diversos espacios y tiempos (Martín-Barbero, 2001).

\section{La juventud como grupo generacional}

La visión generacional ${ }^{3}$ explica la noción de juventud en función de sucesos históricos significativos, es decir, la juventud es definida como un grupo generacional que desde esta

\footnotetext{
3 Kart Mannheim llama la atención sobre los problemas que implica agrupar bajo una misma unidad generacional a todos los individuos de una misma edad. El autor distingue entre conjunto generacional y
} 
visión puede compararse con otras generaciones de jóvenes. Esta perspectiva ha permitido construir algunos estereotipos sobre la gente joven de determinada época, por ejemplo, la "generación perdida» y la "generación X» (década de los noventa), "generación escéptica» (finales de los noventa), "generación de la red» (principios siglo XXI), «los hijos de la libertad», que de acuerdo con Ulrich Beck (1999) son producto de la sociedad moderna. Sin embargo, estas visiones tienden a homogeneizar a la gente joven, señalando características comunes en todas las personas que están ubicadas en la generación joven del momento.

\section{La juventud como praxis diferenciada}

Como reacción a los discursos homogeneizadores de la juventud en su conjunto, se identifica la concepción de juventud en función de la diversidad juvenil, que enfatiza la pluralidad, e incluso la contradicción existente entre los distintos mundos juveniles. Tal diversidad se manifiesta en términos de clase social, de trayectorias vitales de transición hacia la vida adulta y de un conjunto de posicionamientos culturales muy diversos. La categorización de la noción de juventud puede entonces conformarse en función del poder. Se trataría de un acto de recategorización estratégicamente aplicado dentro del campo de la lucha por el poder, de la reproducción. Lucha mediada por los distintos tipos de capital social, cultural, económico, político con que cuentan los jóvenes y en los que se encuentran en constante juego y conflicto al interior del mundo juvenil. Pierre Bourdieu explica la noción de juventud a través de la lucha de poder entre generaciones, porque, según él, la frontera entre juventud y vejez, en todas las sociedades, es objeto de lucha entre la representación ideológica de la división entre jóvenes y viejos (Bourdieu, 1984).

Si bien identificamos cinco tendencias en los enfoques sobre la noción de joven y de juventud, podemos afirmar que esta diversidad obedece a momentos y construcciones históricas determinadas -noción social, cultural e históricamente construida-, que pueden ser identificadas en los trabajos como aspectos imbricados que recurren a diversos constructos conceptuales que posibilitan procesos de construcción y reconstrucción analítica como base para la compresión de los fenómenos juveniles en su complejidad, como se puede identificar en trabajos más recientes (Cfr. Taguenca, 2009; Pérez Islas, 2010; Urteaga, 2012).

La connotación que los autores depositan sobre la noción de juventud responde a estructuras, funciones o procesos en los que los actores juveniles ocupan una función, representan un rol o son gestores o innovadores de prácticas culturales que los hacen aparecer en diversos planos de las escenas. En este mismo sentido, también se puede decir que tales nociones ofrecen o no un papel protagónico a los actores juveniles, es decir: se los puede mirar simplemente como receptores en la transmisión de conocimiento de las generaciones precedentes, se los puede mirar como producto de una reproducción social en la conservación de determinadas prácticas o se los puede analizar y comprender como productores, reproductores y/o transformadores de la cultura. En este último sentido, los procesos de apropiación y objetivación cultural de la

unidad generacional, el primero hace referencia a un conjunto de agentes que forman cierta unidad por las determinaciones positivas y negativas que una misma situación de generación comporta y la unidad generacional refiere a un grupo concreto, con conciencia de sí, que dentro del mismo conjunto generacional actúa de manera similar, apropiándose de manera diferencial del conjunto de experiencias que su pertenencia a un conjunto generacional comporta (Mannheim, 2004). 
juventud son vitales. Por ello, las perspectivas innovadoras resultan de mucha importancia y trascendencia.

\section{Posturas teóricas sobre cultura política}

Al igual que la noción de juventud(es), la cultura política ha sido abordada en una diversidad de estudios en los que se pueden identificar varios enfoques que nos permiten construir una aproximación conceptual que dé cuenta de cómo se la ha concebido. En este sentido, la revisión teórica, conceptual y metodológica se presenta mediante cuatro ejes de análisis: 1) el estudio pionero sobre cultura política, que es abordado desde el enfoque estructural-funcionalista; 2) una mirada a la noción de cultura política desde la Psicología Social y la Antropología; 3) los campos temáticos desde los que se ha estudiado la cultura política en México y 4) la cultura política juvenil.

\section{Perspectiva estructural funcionalista: trascendencia del primer estudio de cultura política}

Las aportaciones teórico-conceptuales de Almond y Verba (1963), en torno a la tipificación de la cultura política permiten describir y vincular la orientación política del ciudadano de acuerdo con sus prácticas y percepciones respecto de ella. De ahí la clasificación de los tipos de cultura política: la cultura parroquial, la cultura política súbdito y la cultura política participante. Este estudio pionero en el campo temático, ha sido objeto de severas críticas, sobre todo desde la investigación social latinoamericana, debido a su visión occidental por sus investigaciones excesivamente centradas en las sociedades europeas y norteamericanas, pero también por el enfoque metodológico (López de la Roche, 2000).

Desde esta perspectiva, el concepto de cultura política ha sido empleado como una categoría residual para designar un conjunto de fenómenos, temáticas y problemas vinculados con objetos políticos bastante complejos y heterogéneos, es decir, como una distribución completa de las actitudes de los ciudadanos a los objetos políticos. ${ }^{4}$ Sin embargo, para entender la vida política de una colectividad no es suficiente con analizar las estructuras de poder y los procesos políticos, sino que es imprescindible ocuparse también de quiénes son los actores políticos, que pueden ser individuos o agrupaciones. Podría decirse entonces que el logro de la cultura política es el interés por el lado subjetivo de la vida política enmarcada en la esfera de lo social, como complemento del lado objetivo de las estructuras, procesos e instituciones directamente observables (Krotz, 2002).

A pesar de que Almond y Verba han sentado las bases teóricas para el análisis de la cultura política, sus aportaciones y postulados comienzan a ser cuestionados y criticados a finales de los años 70 del siglo pasado, y que a juicio de Schneider y Avenburg (2015), estas críticas se sintetizan en tres grandes ejes: a) la definición de los componentes de la cultura política y de la democracia son objeto de un sesgo ideológico y etnocentrista (Welch 1993, citado en Schneider y Avenburg, 2015); b) la tajante separación que realizan los autores entre la cultura política y la estructura y c) la relación de causalidad establecida entre los valores, actitudes y juicios

\footnotetext{
${ }^{4}$ Tales objetos se cuantifican y cualifican con base en un conjunto de conocimientos cognoscitivos, de sentimientos y evaluaciones que tiene una población con referencia a su sistema político. En este sentido, una definición del concepto refiere a un "conjunto de orientaciones específicamente políticas con relación al sistema político y sus distintas partes, y actitudes relacionadas con el rol del individuo en el sistema"(Almond y Verba, 1963: 10)
} 
evaluativos, así como que el comportamiento político denota un "reduccionismo causalista" o una "causalidad recíproca" (Barnes 1988, Barry 1978, Inglehart 1988, Pateman 1971, citados en Schneider y Avenburg, 2015).

\section{Psicología Social como segundo enfoque sobre cultura política}

La Psicología Social constituye un segundo enfoque, en el que se conceptualiza la cultura política a partir de la diversidad cultural, es decir, desde la forma como ésta se piensa y se justifica o desde cómo se ejerce y estructura el poder. Es así que en esta perspectiva cobran importancia dos categorías de análisis: el sujeto político y las identidades políticas, donde se suscita un desplazamiento conceptual para ubicar las categorías de identidad y de sujeto político como referentes ineludibles en el análisis político cultural (Krotz, 2002).

Desde este enfoque el sujeto político se ha estudiado mediante dos perspectivas: la forma en que los sujetos se constituyen históricamente como realidades heterogéneas y variables y desde el tipo de factores culturales que dan cuenta de las modalidades de su constitución y funcionamiento. La primera hace referencia a los procesos de socialización, solo que en ésta se da énfasis no únicamente a los espacios tradicionales -escuela o familia- como tales, sino al resultado de la acción entre ellos. La otra perspectiva se relaciona con las matrices culturales o marcos ideológicos en los cuales y desde los cuales se desencadenan los procesos formadores de las identidades políticas. De esta forma, es factible afirmar que la consolidación de los aspectos que dan origen al funcionamiento de determinados sistemas políticos depende, sustancialmente, de la manera en que dicho sistema es entendido y valorado, subjetivamente, por los individuos que lo hacen funcionar (Gutiérrez, 1996; Rodríguez Kauth, 2001; López de la Roche, 2000).

\section{Enfoque antropológico para el análisis de la cultura política}

Desde una postura antropológica, se identifican pocos estudios sobre cultura política. A finales de los años sesenta desaparecen prácticamente los estudios sobre cultura en América Latina y particularmente en México, debido a que este concepto solía asociarse a determinadas corrientes teóricas de origen anglosajón que provocaban rechazo entre los investigadores latinoamericanos involucrados en las teorías de la dependencia. Sin embargo, a inicios de los años ochenta se retoma la investigación social en torno al tema de la cultura. El logro de los investigadores sociales se manifestó sobre todo en lo concerniente a la cultura popular. Esto puede explicarse a partir del interés paulatinamente creciente por combinar el análisis empírico de los sistemas con el análisis de los actores y por ende, en el lado subjetivo de la vida social, o sea, por el punto de vista de los sujetos sociales (Krotz, 1996; Castro, 2011).

El estudio de la cultura política desde la antropología se ha vinculado al tema del poder, de la subjetividad y de los procesos de producción de sentido, específicamente a la cuestión de lo simbólico. Este tipo de aproximaciones teóricas intenta analizar la cultura política desde una dimensión interpretativa de la cultura, o como señala López de la Roche (2000), las investigaciones en este campo se estudian desde las redes sociales. ${ }^{5}$

\footnotetext{
${ }^{5}$ El autor hace referencia a "las investigaciones de Larissa Adler Lomnitz (1994) reunidas en su libro Redes sociales, cultura y poder: ensayos de antropología latinoamericana, que intentan mostrar, en distintos estratos sociales y grupos ocupacionales, las maneras como se construyen relaciones de reciprocidad,
} 
Schneider y Avenburg (2015) señalan que en la tradición socioantropológica se ubican autores como: Fernando Castaños (1997), Norbert Lechner (1997), Marc Ross (2010), entre otros, pero que en cuanto a los aportes más interesantes y recientes, sobresalen los de Ross, quien se ha apoyado en la conceptualización de cultura de Clifford Geertz (2003). En especial, de acuerdo con Schneider y Avenburg (2015: 115), "Ross subraya que la importancia de la cultura en el estudio de la política radica en que proporciona a las personas un marco para organizar sus mundos. Contrariamente a los postulados más clásicos, el autor no se refiere a la 'cultura política' per se, sino al 'análisis cultural de la política'. Para llevarlo a cabo, sostiene la necesidad de poner énfasis en cómo, a través de significados intersubjetivos compartidos, los actores entienden y actúan 'políticamente' en sus mundos cotidianos".

Es con base en tales revisiones -desde lo propiamente politológico, lo antropológico y lo sociocultural-, que Cecilia Schneider y Karen Avenburg se posicionan argumentando que la cultura política debe ser analizada como "una matriz de significados encarnados en símbolos, prácticas y creencias colectivas mediante los cuales las personas y las sociedades se representan las luchas por el poder, ponen en acto las relaciones de poder, la toma de decisiones, cuestionan o no los valores sociales dominantes y resuelven o no el conflicto de intereses" (2015: 127). Aspectos que de acuerdo con lo planteado, permiten conformar líneas analíticas para comprender los procesos de objetivación de la cultura política, en cuanto a lo posible, lo concebible y lo realizable

En concordancia con esta última perspectiva (socio-antropológica-cultural), planteamos algunos interrogantes que sirvieron como base en el desarrollo de la investigación que dio origen al presente artículo: ¿cuáles son esos procesos histórico-culturales que van conformando a los sujetos que pasan por un determinado espacio institucional, cuyas trayectorias escolares y familiares se conjugan (con esa experiencia institucional) para cargar de sentido sus concepciones, valores, actitudes y por ende, las prácticas relacionadas con la esfera de lo político?

\section{Campos temáticos en el estudio de la cultura política en México}

En México, el uso del término cultura política es relativamente reciente, aunque el tema ha sido discutido desde hace tiempo en nuestro país. La mayoría de los estudios se abordan en un sentido bastante difuso en la esfera de los conocimientos, percepciones, creencias, imágenes, opiniones, actitudes, afectos, temores, deseos, expectativas, preferencias, anhelos y evaluaciones que los actores políticos tienen respecto a la esfera del poder.

Un primer campo temático para estudiar la cultura política en México se desprende de los estudios que han intentado describir y analizar el carácter nacional del mexicano. El estudio de los partidos políticos como organizaciones nacionales, los movimientos y situaciones sociales y políticos más amplios, así como los derechos humanos, son ejemplos para comprender los diferentes obstáculos por los que atraviesa una sociedad en constante proceso de reenculturación política democrática. Sin embargo, coincidimos en que estos campos temáticos no son los únicos en los que se pueden encontrar elementos teóricos para el examen de la cultura política.

solidaridad, lealtad, ayuda mutua, confianza, redes de conexiones sociales y familiares, ya sea de tipo horizontal (intraclase) o de tipo vertical (interclase)" (López de la Roche, 2000: 109). 
Un segundo campo temático tiene relación con el estudio de los diferentes segmentos, sectores sociales o grupos de población en los que se hace presente la cultura política. Las investigaciones sobre el sector de los obreros tienden a reconstruir la historia de sus luchas y su papel en la transformación democratizadora de las organizaciones obreras en particular y de la vida política en general. Los estudios sobre el sector de los campesinos, cuya orientación teórica estaba tan centrada en el aparato estatal que, a pesar de la evidencia etnográfica, veía a la población rural como un ente políticamente pasivo y simple víctima de los aparatos del Estado. El auge en el campo de los estudios de la mujer o estudios de género ha contribuido también al conocimiento de la cultura política. Sin embargo, no sucede de igual forma con otros sectores de la población, donde los estudios de cultura política siguen siendo muy reducidos, es el caso de los pueblos indígenas, ${ }^{6}$ el sector de los niños y jóvenes.

\section{Algunas temáticas de investigación sobre cultura política juvenil}

Dentro de los estudios de cultura política y prácticas ciudadanas, que incluyen de algún modo a la juventud como objeto de estudio, identificamos como antecedente más remoto la Encuesta preelectoral de 1988 de Anna María Fernández Poncela, realizada desde un enfoque funcionalista. En este estudio se identifican algunos indicadores que orientan el análisis de las prácticas juveniles con relación a la legitimidad política, la participación electoral, los niveles de escolaridad y la confianza o desconfianza que se tuviera respecto de alguna situación o actor político en particular.

Otro estudio relevante por sus aportaciones es el de Víctor Manuel Duran Ponte (1998), quien desde la teoría de la Rational Choice analiza las perspectivas y prácticas de los estudiantes universitarios de la UNAM. Sus conclusiones invitan a reflexionar sobre la diversidad de aspectos que se ponen en juego al momento de analizar las concepciones y prácticas que sobre cultura política tiene este tipo de población. Identificamos también el estudio denominado Ciudadanos y Cultura de la Democracia. Reglas, Instituciones y Valores de la Democracia, realizado por Yolanda Meyenberg y Julia Flores (1997), quienes desde una perspectiva funcionalista identifican distintas formas en que los jóvenes otorgan o no legitimidad política.

Una revisión puntual sobre los estudios de tipo encuesta nos llevaron a identificar seis: 1) el Latinobarómetro, iniciado en 1995; pionero no solo en México, sino en América Latina); 2) Los Mexicanos de los Noventa, desarrollado a finales de 1996, estudio nacional que al parecer está muy relacionado con el anterior; 3) Ciudadanía y cultura de la democracia. Reglas, instituciones y valores de la democracia, también conocido como Encuesta Nacional de Valores de la Cultura Política, trabajo organizado por el Instituto Federal Electoral y llevado a cabo por la UNAM. 4) Cultura política y prácticas ciudadanas en México, realizado en 1996 por la Secretaría de Gobernación con el apoyo del Instituto Nacional de Estadística Geografía e Informática (INEGI), que como parte complementaria desarrolló un seminario de análisis, en el que participaron diversas instituciones, tales como: la Universidad Nacional Autónoma de México (UNAM), la Universidad Iberoamericana, la propia Secretaría de Gobernación y varios expertos tanto nacionales como extranjeros. 5) Cultura política de los alumnos de la UNAM (mencionada en

\footnotetext{
${ }^{6}$ Actualmente existen estudios sobre población indígena y ciudadanía con enfoque intercultural, ejemplo de ello son los artículos incluidos en los libros editados por Luis Enrique López (2009) y Gunther Dietz, Rosa Guadalupe Mendoza y Sergio Téllez (2007).
} 
líneas anteriores); aun cuando no es un estudio de alcance nacional, constituye un insumo de reflexión particular, pues el autor (Durand Ponte, 1998) particulariza el estudio de la cultura política en estudiantes universitarios, lo que permite contar con referentes de acotación a una población particular, adscrita a una institución, además de ocuparse de la población juvenil. Finalmente, 6) la Encuesta Nacional de Juventud 2000 -y algunos elementos y resultados de la versión 2005 y las subsecuentes-, en especial del apartado llamado Cultura política, organización y participación juvenil (Reguillo, 2000), consideramos que ésta es una fuente de especial atención. Por un lado, en cuanto a la construcción teórico- metodológica que realiza Roxana Reguillo en la conformación y definición de indicadores y por otro, porque los resultados que arroja constituyen una fuente de contraste con la población juvenil que se defina como objeto de estudio.

Respecto a los indicadores considerados en los estudios revisados, se encontró como una constante que estos pueden dar cuenta de lo que sucede con relación a la cultura política. Por ejemplo, en cuanto a la legitimidad política, los valores políticos, los conocimientos o la información, la participación electoral o política, las valoraciones o evaluaciones del sistema político, la confianza o desconfianza que se tenga respecto de alguna situación o actor político en particular y la relación de estos con los niveles de escolaridad y condiciones socioeconómicas. Solo recientemente -bajo una perspectiva crítica, y en pocos estudios- se empieza a considerar la 'socialización política', la 'movilización cognitiva' o como lo abordan algunos autores, la 'cultura política en movimiento' (Reguillo, 2002, Pérez Islas, 2006), o la 'desafiliación político-institucional' (Reguillo, 2010), que consideramos está relacionada con el proceso de conformación de la identidad política.

Para cerrar este apartado y con base en la revisión presentada, la postura teórico-conceptual que se asume en la construcción de este trabajo, se ubica en una perspectiva socio-históricocultural, donde la cultura política tiene sus bases en imbricaciones axiológicas y praxiológicas orientadas por principios, valoraciones, concepciones y fines, construidos colectivamente y que desembocan en regulaciones, normas, prácticas, acciones y hábitos en torno al poder -acción social-, su ejercicio y su interpretación cultural: símbolos, signos y significados, desde lo individual en lo colectivo. Tales procesos de regulación, al ir institucionalizándose van conformando reglamentaciones que orientan el ejercicio de poder y la participación social (ejercicio político). Los sujetos, por tanto, pueden objetivarse como reproductores (ejercicio mecánico de lo instituido) y/o productores (proceso de transformación de prácticas institucionalizadas, la cultura política en movimiento) de ciertas prácticas de cultura política.

Al ubicar la cultura política como un proceso de formación que se va construyendo a lo largo de la vida de los individuos (trayecto experiencial), la temática necesariamente debe considerar, también, el campo de la educación (posición que ocupamos en la generación de conocimiento), por tanto, hacemos una breve exploración al respecto.

\section{Ciudadanía y cultura política en el campo de la educación}

El tema de la cultura política, relacionado con los jóvenes y la educación, ha cobrado atención apenas a finales del siglo pasado, a pesar de que este grupo de población ocupa un lugar 
preponderante en la distribución poblacional de México, ${ }^{7}$ además de que los jóvenes menores de 18 años son sujetos potenciales en la integración del padrón electoral y, en especial, de las decisiones políticas que se tomen en el país. Dentro de la revisión que se hace al respecto, se reconoce que el estudio sobre politización del niño mexicano, realizado por Rafael Segovia (1975), hace ya cuatro décadas, no ha incentivado el desarrollo de trabajos similares, aunque se cuenta con las consultas infantiles y juveniles desarrolladas en los periodos electorales (desde finales de los ochenta). No obstante, éstas no han alcanzado las características y rigor metodológico con el que se llevó a cabo el estudio de Segovia. Además de que la concepción de la educación o la formación cívica se han modificado (Rodríguez Mckeon y Elizondo, 2010). En los estudios recientes sobre la juventud, principalmente en México, se muestra que existe una gran diversidad al interior de tales investigaciones y que algunas de ellas señalan interesantes observaciones para derivar nuevas vetas investigativas o definir agendas para la profundización en las concepciones y prácticas de la política (Trejo, Arzate e Itati, 2010).

Si bien Krotz (2002) señala que no existen estudios respecto a la formación escolar del civismo y la cultura política, es necesario mencionar que este tipo de trabajos generalmente no se refieren al tema desde tal perspectiva, pues se centran más en nociones que tienen que ver con la formación de valores, con derechos humanos, educación democrática o ritos escolares, además de que tales trabajos, en su mayoría, son tesis escolares desde el nivel de licenciatura hasta doctorado $y$, aunque su difusión editorial es reciente, se les identifica y reconoce únicamente en el ámbito de la educación formal. ${ }^{8}$ Resulta de gran utilidad reconocer que tanto en el ámbito nacional como internacional han proliferado trabajos que se ocupan de dar cuenta sobre estas temáticas y que en gran parte de ellos se pugna por una educación para la democracia. ${ }^{9}$

Aunque también hay que tener presente que si no se tiene una identificación clara de lo que es e implica el estudio de la cultura política, entonces es difícil diferenciarla de otros campos de investigación. El trabajo realizado por Krotz $(2002)^{10}$ ofrece un panorama general de la investigación sobre cultura política en México. La manera como se aborda esta temática parece muy ilustradora, ya que se ocupa de explicitar un tanto los orígenes del estudio de la cultura política como la forma en que este campo se ha desarrollado desde diversas disciplinas.

Respecto a las discusiones teóricas que se identifican en los trabajos que desarrollan el tema de la cultura política se encuentran cuatro tendencias: a) Dada la diversidad temática, es común que se presente el término sin explicación alguna. b) Existen trabajos que se dedican

\footnotetext{
${ }^{7}$ De acuerdo con las Proyecciones de Población 2010-2050 del Consejo Nacional de Población (CONAPO) en México habitan aproximadamente 38.2 millones de jóvenes, de entre 12 y 29 años de edad, que tienen una serie de demandas a atender por parte del Estado (IMJUVE, 2015: 6).

${ }^{8}$ Por ejemplo el trabajo de García Salord y Vanella (1992) sobre normas y valores en el salón de clases, o el de Molina (2000) que refiere a valores para la democracia en educación primaria o los de Rodríguez McKeon (2009), Rodríguez McKeon y Elizondo (2010) y Molina (2011), entre otros, que abordan cuestiones respecto a la educación democrática y la ciudadanía en la educación básica. Especial atención merece el libro de Yurén (2013), pues constituye un referente conceptual esencial en el campo de la educación desde la ética política.

${ }^{9}$ Una referencia rápida a este tipo de trabajos la encontramos en instituciones como la UNICEF, la AMNU, la Secretaría de Educación Pública en México o del Ministerio español, por mencionar algunas, además de importantes autores tales como: Sarramona (1993), Schmelkes (1997), Yurén (2013, 2014), entre otros.

${ }^{10}$ Otras versiones que coinciden con esta revisión son los trabajos de López de la Roche (2000) y de Schneider y Avenburg (2015).
} 
exclusivamente a analizar y discutir el concepto. c) Los que se ocupan de presentar el material empírico y suelen dar una breve exposición del significado conceptual. d) Solo en contadas ocasiones se establece un debate con intentos contemporáneos de estudiar la cultura política mexicana.

Dentro de estas dos últimas tendencias se reconocen, a su vez, cuatro grupos: 1) Los que debaten con y a partir de la concepción original de Almond y Verba. 2) Los que discuten el concepto, en ocasiones a partir del referente anterior, con la intención general de entender la cultura política mexicana. 3) Los que parten de y combinan diferentes enfoques para llegar a una definición de lo que entienden por cultura política. 4) El último grupo aborda temas, conceptos e ideas que son parte de la discusión sobre cultura política o que se encuentran íntimamente relacionados con su problemática, tales como la legalidad, identidad nacional o reconstrucción de los mapas políticos (Krotz, 2002).

En cuanto a las disciplinas que se ocupan del tema, se reconoce que éste no ha sido visto desde un único campo -la politología-, sino que existe una visión multidisciplinar, en la que se observan múltiples convergencias y superposiciones, en cuanto a conceptos y procedimientos de investigación. No existe un deslinde disciplinar en la presentación de resultados pues, por ejemplo, en las revistas especializadas se presentan tanto un artículo de la disciplina temática que les ocupa como de otra temática próxima o relacionada. No obstante estas acotaciones, la producción investigativa se identifica principalmente en tres disciplinas: la sociología, la antropología sociocultural y la psicología social (dejamos de lado los estudios que competen de manera particular al campo de la ciencia política).

Existen otras disciplinas que recientemente se han ocupado de la cultura política. Una de ellas es la lingüística, desde la teoría de las ideologías y desde el análisis del discurso. Con ella se ha incursionado en la cosmovisión política de grupos indígenas y para el estudio de la vida parlamentaria y de lo político en la cultura popular. ${ }^{11}$ Desde la filosofía ${ }^{12}$ existen estudios para esclarecer cuestiones conceptuales referidas a la esfera del sujeto político y de la nación, en especial de la ciudadanía, partiendo en sus análisis y reflexiones de la observación de la vida política en el país y de la bibliografía especializada generada en las ciencias sociales. Desde el campo del derecho, encontramos los que refieren a los derechos de los indígenas y, especialmente, con cuestiones que tienen relación con lo jurídico. Resulta importante mencionar que también se han desarrollado estudios desde la perspectiva histórica; mediante ellos, se pueden identificar las continuidades y las rupturas que refieren a la cultura política mexicana.

Finalmente, desde el campo de la educación, como eje disciplinar de investigación, se han hecho estudios relacionados con la cultura política, que se han ocupado sobre todo de las instituciones encargadas de la educación de los adultos en sus diferentes modalidades, así como de los procesos educativos relacionados con la organización popular (Krotz, 2002). En los estados del conocimiento del Consejo Mexicano de Investigación Educativa, encontramos que se empieza a hacer referencia a la producción de algunas investigaciones en este campo (Molina y Heredia, 2013), esto a diferencia de los trabajos reportados en el periodo anterior (Tapia, 2003,

\footnotetext{
${ }^{11}$ Para mayor información al respecto, consultar Krotz (2002: 39) y los estudios específicos que aparecen citados en tal apartado y otros que hemos referido en este trabajo cfr.: López (2009); Dietz et al. (2007).

${ }^{12}$ Los trabajos de Yurén $(2013,2014)$ son muy ilustradores en este campo disciplinar.
} 
Salinas, 2003). También se encuentran trabajos desarrollados en las universidades (cfr. Monsiváis, 2004) o dirigidos a sus estudiantes. ${ }^{13}$

Con base en los referentes anteriores, coincidimos con Krotz (2002) cuando afirma que el estudio de la cultura política en México es un campo científico que se encuentra todavía en su fase inicial y, como señala, es motivo de interés de una variada cantidad de disciplinas que se ocupan de ello, además de que la difusa distinción de las fronteras disciplinares o recortes analíticos en ocasiones dificulta la distinción entre análisis científico y comentario político, entre lo que sería un estudio metódico y un ensayo intuitivo, entre una descripción y el análisis de la realidad existente, con lo que sería una propuesta de acción para lograr determinadas metas políticas. Lo que, de acuerdo con el autor, nos hace ver que la indiscriminada proliferación de este tipo de trabajos evidencia el manejo de temas a veces poco articulados entre sí y alejados de la discusión teórica. Además, "... la rapidez con la que se han estado -y se siguen- dando los cambios en la vida política y jurídica del país, exige a los científicos sociales reenfocar constantemente la problemática, lo que también frena la consolidación del campo" (Krotz, 2002: 43).

A partir de este breve esbozo, consideramos que es necesario poner atención y cuidado, por un lado, sobre el objeto de estudio como tal y, por otro, en la conformación conceptual y metodológica. Queda clara la necesidad de asumir postura con relación a lo que implica el estudio de la cultura política y, en especial, de la cultura política juvenil -nuestro objeto de estudio. Por tanto, este trabajo no opta por las tendencias y cuestiones partidistas como componentes de la cultura política, sino que se ocupa de la formación socio-educativa-cultural, que implica la conformación de una identidad política, cargada de principios y valores -signos y significados que podrían estar presentes en las prácticas de los sujetos de estudio y los procesos que ellos van conformando. De la misma manera, se reconoce que el estudio de este campo temático debe desarrollarse desde una perspectiva interdisciplinar, que considere los aspectos socioeducativos con una mirada antropológica (cultural), articulados por lo que se identifica como Ciencias de la Educación.

A continuación compartimos un ejercicio para construir una herramienta teórico-metodológica (como estrategia de concreción de una propuesta comprensivo-analítica), como un esfuerzo por estudiar un segmento de población que se ubica en el ámbito juvenil, una población que en su mayoría es de origen rural (conformación histórico-cultural), que ha concluido un nivel educativo formal (secundario o de bachillerato) y que transita por un proceso formativo institucional (trayecto formativo). Tal experiencia le va abonando sentidos axiológicos que orientan su praxis en la esfera cotidiana y su relación con la política constitutiva de la ciudadanía.

\section{Sujetos sociales y dimensiones de análisis en la cultura político-ciudadana del Instructor Comunitario (IC)}

Si partimos del supuesto de que la cultura política es una forma de expresión/objetivación del tipo de ciudadanía que se ejercerá o que se está ejerciendo, luego intentaremos relacionar la

\footnotetext{
${ }^{13}$ Algunos ejemplos son los estudios sobre la cultura política de los estudiantes de la UNAM, o los producidos por la Universidad Iberoamericana (campus Puebla y Santa Fe) o los de la propia Universidad Autónoma del Estado de Hidalgo.
} 
categoría juventud con la de ciudadanía, en torno a su constitución y vinculación con algunas categorías sociales. En este sentido, la ciudadanía es conceptualizada como un campo común, en el que confluyen las esferas de lo público, lo político y lo privado, ya que sus sentidos se forman en la interacción de instituciones, grupos sociales, industrias culturales e individuos particulares. Vista así, los procesos formativos de cultura política juvenil podrían abordarse visualizando la construcción de ciudadanía de manera abierta y continua, en la que es posible una integración de lo multicultural en un plano de educación política.

Para el caso que nos ocupa, la intención y significado de lo 'joven' toma como dimensión la diversidad, puesto que no se concibe a la juventud como un ente general y homogéneo, además de que la ciudadanía $y$, por ende, la(s) cultura(s) política(s) del particular no se adquiere(n) con la edad. Esto es: se sostiene que los adolescentes y jóvenes no esperarán a ser adultos (mayores de 18 años) para entonces conformar su cultura política y, por tanto, hacer lo que les corresponde como ciudadanos en ejercicio pleno de sus derechos y obligaciones, sino que se encuentran en un proceso de formación permanente y a lo largo de la vida, que de manera continua y experiencial los va (y se van) constituyendo como sujetos de acción política.

Con base en lo anterior, nos abocamos a las dimensiones civil, social y cultural de la ciudadanía, y no precisamente a la dimensión política, particularmente porque los jóvenes que participan en los espacios alternativos de formación, en este caso los Instructores Comunitarios (IC) ${ }_{1}{ }^{14}$ no se encuentran dentro de esta última dimensión, ya que legalmente no son ciudadanos en ejercicio -son menores de edad según la Constitución Política mexicana y, por ende, aún "no pueden ejercer sus derechos como ciudadanos-políticos". No obstante, estos jóvenes desarrollan en la práctica cotidiana de su labor educativa, una serie de actividades que trascienden -en lo formal- la construcción y el ejercicio de la ciudadanía (en todas sus dimensiones), la cual es matizada por un fuerte compromiso social. Por tanto, se parte del supuesto de que la ciudadanía no es cuestión de edad o estatus. No se adquiere al cumplir los 18 años, ni con 'el contar con la credencial para votar', es parte de un proceso que se da a lo largo de la vida, es parte de la formación cívica, de la convivencia personal, familiar y sociocultural. En general, cada uno de los espacios de convivencia constituye momentos y situaciones en la formación de culturas políticas particulares.

Como se ha señalado, existen diversas tendencias para referirse a los jóvenes y, en especial, para remitirse a las culturas juveniles, pero en este caso, los jóvenes que llegan a ingresar al CONAFE y que logran transitar por la experiencia de ser Instructor Comunitario (IC), no son cualquier tipo de joven, se puede decir que son jóvenes que constituyen grupos de subculturas con perspectivas de vida diferenciadas, que en este trayecto conforman identidades proyecto (Castells, 2004), en las que predomina el compromiso social y la forma de hacer en su vida como ciudadanos con culturas políticas particulares. Son jóvenes que a los 15 años dejan de vivir con

\footnotetext{
14 El Consejo Nacional de Fomento Educativo (CONAFE) es un organismo federal descentralizado de la Secretaría de Educación Pública (SEP), que tiene entre sus atribuciones llevar educación básica comunitaria a localidades pequeñas - principalmente rurales- del país. Su esquema de operación está basado en la captación -y participación voluntaria- de jóvenes egresados de secundaria o bachillerato (sujetos de estudio identificados desde 2014 como Líderes Comunitarios del CONAFE), que a cambio de la prestación del servicio educativo reciben un apoyo económico para dar continuidad a su formación académica (educación formal posterior al último nivel de estudios alcanzado, el periodo de apoyo está definido por los años de prestación del servicio, tres por cada año de servicio).
} 
sus padres, participan en un proceso de capacitación con el que, después de dos meses, ya son los 'maestros de la comunidad', optan -como parte del servicio social educativo- por vivir en una comunidad alejada de los servicios básicos (de bienestar), se encuentran a grandes distancias de sus familiares y, en la mayoría de los casos, no tienen oportunidad de visitarlos. Estos jóvenes pasan por una serie de situaciones que los hacen permanecer y fortalecerse como personas y ciudadanos o, como lo hacen algunos, dejan la comunidad y vuelven a sus hogares privándose de la oportunidad de ser instructores comunitarios.

La noción categorial de juventud y su reconstrucción epistemológica, articulada con la de institucionalidad del CONAFE (instituida, instituyente e institucionalizadora), ofrece elementos para caracterizar la formación y formalización de los procesos de socialización-incorporación, objetivación-apropiación y transformación-movimiento-objetivación de la praxis, no solo educativa, sino social y política de los jóvenes que participan en este tipo de proyectos.

Por tanto, se reconoce que joven-IC constituye una categoría compleja y multirreferencial, que en la actualidad está trastocada por la globalización, como contexto en el que se desarrollan nuevas identidades e identificaciones juveniles. Asimismo, se reconoce que la cultura, como eje de construcción del objeto, también es diversa y multirreferencial, conformada por ese entramado pluricultural, multicultural e intercultural en el que conviven y se expresan nociones de ciudadanía en un espacio de formación educativa.

Con base en lo anterior, es posible dar cuenta de los principios, creencias, valores, concepciones y fines que orientan la objetivación de las prácticas sociales en los procesos de conformación de cultura política juvenil de los IC. En tal conformación, consideramos que el plano de formación axiológica y, por ende, de objetivación de la eticidad, se da mediante un proceso que a su vez está integrado por los procesos de socialización, enculturación, cultivo y formación (Yurén, 1995, Molina, 2000), tanto formal como informal y no formal, de los sujetos que participan en los programas educativos del CONAFE.

\section{Las esferas de poder como referente conceptual}

Como se dijo en un apartado anterior de este trabajo, la cultura política es para nosotros el proceso de conformación de valoraciones, disposiciones y dispositivos de participación y compromiso social que va desarrollando el sujeto a lo largo de su vida. Estos aspectos se objetivan con base en sus trayectorias: percepciones de vida (dimensión axiológica) y las actitudes, acciones y prácticas que de ella se derivan (dimensión praxiológica). La cultura política es una categoría que está íntimamente relacionada con la de ciudadanía, la cual a su vez, conceptualizamos como aquella que conforma a los sujetos particulares desde sus dimensiones civil, política, cultural y social, en el proceso de construcción autónoma de la persona en el que se activan derechos y obligaciones. Los primeros, como garantías que se le otorgan y asume el sujeto para su actuar en un marco de acción legítima y legal; las segundas, como marco o estructura común de acción política.

De acuerdo con este enfoque, recurrimos a la noción de esferas de poder, como esas dimensiones deconstructivas y de empoderamiento de los sujetos en su accionar cotidiano. Es decir, que las esferas de poder refieren al "contexto de interacción o medio institucional en y a través del cual el poder da forma a las capacidades de las personas; moldea y circunscribe sus perspectivas de vida y su participación efectiva en la elaboración de las decisiones públicas" (Held, 1997: 212). Por tanto, la institución CONAFE ofrece un espacio de formación y contenido 
donde los jóvenes construyen sus perspectivas de vida ${ }^{15}$ y formas de participación. En este proceso de conformación se encuentra, como eje de construcción del sujeto, la autonomía con su antagónico, la nautonomía, cuyas dimensiones se tensionan entre una formación democrática y una formación tradicional lineal, que matizan sus percepciones y prácticas en lo que a cultura política refiere.

La nautonomía, conceptualizada como esas formas de "producción y distribución asimétrica de perspectivas de vida, que limitan o trastocan las posibilidades de participación política" (Held, 1997: 212) constituye una categoría central para el análisis respecto a los procesos de conformación de ciudadanías y por ende, de culturas políticas juveniles. Si recurrimos a este concepto como referente analítico, aplicado a los jóvenes-IC, identificamos que se les presentan situaciones que limitan el proceso de conformación autónoma de los sujetos y las posibilidades de participación política democrática. En el campo de la educación, encontramos de forma recurrente que se hace referencia al propósito primordial de formar sujetos autónomos, sin embargo, poco se revisa lo que impide que este fin sea alcanzado. Por lo cual, analizar tanto las fuentes de poder como sus esferas permite contar con referentes para dar cuenta sobre sus formas de objetivación, debido a que éstas

... inician, mantienen y transforman la producción y distribución del poder -por medio de la organización y el control de ciertas reglas y recursos- dentro y a través de las distintas esferas. Los elementos del contexto de interacción de una esfera particular pueden operar de forma independiente; es decir, las relaciones y estructuras de poder de esa esfera, pueden generarse y ser aplicadas internamente... [Como lo son las aplicadas en y por el CONAFE]. Sin embargo, ciertas esferas de poder pueden dar origen a presiones y fuerzas que se extienden más allá de sus fronteras y moldean y delimitan otras esferas. [...] Estas esferas de poder se convierten en cierta medida en la fuente de poder de otras esferas (Held, 1997: 212).

Las siete esferas de poder, por su parte, ofrecen referentes de búsqueda, en la medida que junto con ellas se pueden identificar los indicadores que le dan sentido a los procesos, acciones y contenido en la conformación de cultura política y de ciudadanía; ofrecen referentes sobre las posibilidades o no en la conformación de la autonomía de los individuos, en la apertura o cierre para el desarrollo de sus perspectivas de vida. Las esferas a que hacemos referencia son las ocho que distingue David Held (1997): el cuerpo, el bienestar, la cultura, las asociaciones cívicas, la economía, las relaciones coercitivas y la violencia organizada, así como las instituciones legales y regulatorias.

En cuanto a la esfera del cuerpo, distinguimos que considera el cuidado del bienestar físico y emocional, cuya perspectiva de vida o aspectos de supervivencia está relacionada con la geografía, raza, género y clase social, entre otros. Considerando esta esfera de poder, los jóvenes-IC, deben 'aprender a accionar' el derecho a contar con un ambiente limpio y saludable. Respecto a la esfera del bienestar, se vincula especialmente con la dimensión social, en la que se

${ }^{15}$ Las perspectivas de vida son esas oportunidades con las que cuenta una persona para participar de los bienes económicos, culturales y políticos socialmente generados: recompensas y posibilidades características de una comunidad, que se van manifestado en diversas esferas de poder y ponen en juego una serie de derechos y valores en el proceso de construcción hacia la autonomía y para la participación como ciudadanos de una comunidad política democrática (Held, 1997). 
presta especial atención, como dominios de acción habilitados por los derechos al desarrollo de las aptitudes y talentos, al cuidado integral de la infancia, el acceso universal a la educación y los servicios a la comunidad. Esta esfera cobra especial relevancia debido a que los jóvenes-IC vivirán en comunidades marginadas carentes de algunos servicios básicos de bienestar.

La tercera esfera, la cultura, está directamente relacionada, por un lado, con el hacer propio de las comunidades en las que se presta el servicio educativo y, por otro, con el proceso de conformación identitaria -como experiencia formativa- de los jóvenes-IC y el desarrollo de las actividades programadas como parte de los ambientes educativos. La esfera de las asociaciones cívicas es aquella en la que se ejercitan los derechos a la libertad de formar o unirse a asociaciones autónomas, la pertenencia activa a las asociaciones cívicas y a la libertad de tener información.

En cuanto a la esfera de la economía, se ocupa de las condiciones socioeconómicas de las familias tanto de los jóvenes-IC como de la comunidad, ya que mediante ellas se revisa el derecho a tener un salario mínimo garantizado, la diversidad de formas de consumo y propiedad productiva, así como el acceso a los flujos de recursos productivos y financieros, cuyo dominio de acción se relaciona con la capacidad de emprender diversas actividades económicas sin sufrir del riesgo de la vulnerabilidad inmediata.

La esfera de las relaciones coercitivas y la violencia organizada refiere de manera particular al derecho a una convivencia pacífica, la identificación de su naturaleza y la resolución del conflicto o situación. Activa el derecho a una coexistencia pacífica en la que se garantice la seguridad física y las relaciones no coercitivas. En estos tiempos y, en particular, en el contexto mexicano, estas perspectivas de vida para la activación del derecho resultan cruciales, pues se han activado condiciones que ofrecen predominio para la nautonomía en este campo. La última esfera refiere a las instituciones legales y regulatorias. Incluye los derechos habitualmente llamados políticos y ciertos derechos que suelen denominarse civiles, como lo es, por ejemplo, la igualdad ante la ley, el respeto por ella y las condiciones para la participación. En esta esfera se consideran, esencialmente, los derechos que permiten dar cuenta de lo que sería la cultura política de los sujetos de investigación.

\section{Noción de Constelaciones como herramienta metodológica}

Como hemos planteado, las esferas de poder han sido parte de la base conceptual que permitió construir y comprender el objeto de estudio. Si bien David Held no hace una referencia explícita a lo que entiende por constelaciones de poder $\mathrm{y}$, por ende, a sus componentes, en este trabajo se desarrolla una aproximación conceptual, mediante la que se identifica la noción de agrupación. En este caso, refiere a la agrupación de indicadores que es equiparable con una clasificación tipográfica. Es decir, de acuerdo con las coincidencias del grupo se deriva una nominación particular de la agrupación. Otra categoría es la de posición, en el sentido de ir analizando el lugar de ocupación de los indicadores, de acuerdo con el tipo de respuesta que dan los encuestados y el tipo de relaciones que se van articulando dependiendo de la fuente de producción de sentido que se genera con el andamiaje de la primera relación de indicadores (constelación simple) y las que se van derivando de ellas.

Ahora bien, para presentar la agrupación de datos debemos preguntarnos de qué manera se construyen las constelaciones de la cultura política. Para ello se parte de la identificación simple de relaciones entre variables, las cuales después de ser revisadas desprenden otras relaciones. 
Abordar una relación particular para ir construyendo la constelación implica tener presente que cada relación abordada va desprendiendo a la otra $y$, por tanto, las relaciones que se encuentran en una pueden contribuir para que se desprenda otra.

Estas relaciones construyen redes de relaciones, es decir, partimos de que hay una variable o categoría (estrella) 'madre', ubicada de acuerdo con la esfera de poder de que se trate, que predomina para la determinación de relaciones (la que tiene más luz o la que tiene mayor influencia sobre las demás), para entonces así determinarlas y, por tanto, armar la constelación y la articulación entre constelaciones. Así, al ir aproximándose a la explicación y comprensión del objeto de estudio, las relaciones se van complejizando y, en consecuencia, se busca incluir la mayor cantidad de variables que den cuenta de las relaciones e interpretaciones de la cultura política y sus respectivas relaciones sociales.

Es importante mencionar que las fuentes de información están constituidas por referentes empíricos tanto de tipo cuantitativo como cualitativo y que la revisión e interpretación debe estar conformada desde esos dos referentes. Lo que posibilita la construcción de mapas mentales que representan las constelaciones (Molina 2008; Molina y Ponce, 2011).

\section{Algunos resultados}

Con base en lo anterior, a manera de ejemplo -por cuestiones de espacio- presentamos el análisis de algunos resultados a partir de la agrupación temática que se da de acuerdo a los datos arrojados (articulación cuantitativa-cualitativa). Como aspecto contextual y de ubicación del objeto de estudio, identificamos a los jóvenes-IC que comprendieron la muestra -bóveda en la que se ubican las constelaciones de acuerdo con la población objetivo-corresponden al 10\%, elegidos al azar, de los 2883 jóvenes que participaron en los programas educativos del CONAFE y que se ubican en las 20 sedes que integran las regiones en el estado de Hidalgo-México.

La población en su mayoría son mujeres $(69,1 \%)$, el nivel educativo en el que se encuentran estudiando corresponde principalmente al bachillerato (40\%), seguido del universitario $(23,2 \%$ en proceso y $7,3 \%$ concluido) y con una presencia mínima de estudios correspondientes a carreras técnicas o comerciales (9,5\%). La mayor parte de las familias son de estratos socioeconómicos bajos, debido a que sus percepciones son menores al salario mínimo (54 \%) o ubicadas en el mínimo (25,9\%); sus niveles de escolaridad no alcanzan más que primaria (padres 57,2 \%, madres 56,8 \%); cuatro de cada 10 madres se dedican al hogar (en este caso, $39,4 \%$ no dio respuesta); respecto al padre, las actividades se diversifican: jornalero campesino $(27,8 \%)$, trabajador por cuenta propia $(20,8 \%)$, empleado en el sector privado (11,2\%) y trabajador de tiempo parcial (27,5\%). El resto, aunque en proporciones mínimas, lo ocupan padres de familia con mejores posiciones laborales y salariales, como son: trabajadores con cargo en el gobierno (3,1\%), profesionales independientes (1,9\%) y funcionarios de gobierno $(0,8 \%)$; jubilados y trabajadores sin pago $(6,9 \%)$ también son padres de jóvenes-IC. Con estos breves datos contextuales podemos comprender por qué se forma la primera constelación

\section{Primera constelación: El inicio, de la valoración de la labor a la importancia de realizar la tarea}

Esta constelación se construyó a partir de la valoración que el joven-IC tiene de su actividad, encontrándose que lo más valioso son las experiencias que los hace crecer como personas (29\%) o que los hace tener mayor responsabilidad social y personal $(25,9 \%)$ y que los lleva a 
conocer otras realidades (19,3\%). Con lo que se concluye que los IC se encuentran en un proceso de construcción de la individualidad para el cultivo de la persona, puesto que centran su valoración e interés en el crecimiento personal, más que en las actividades propias del programa o en la posibilidad del trabajo comunitario. Lo cual, como elemento de conformación identitaria, constituye una base de reconocimiento de la persona que aquilata para su formación futura. Constelación derivada de la primera y segunda esferas de poder-cuerpo y bienestar-: la razón principal de ingreso al programa constituye el logro de sus expectativas en la perspectiva de vida sobre el derecho a la formación personal, contar con recursos para el cuidado de su salud y asegurar un nivel de bienestar al tener posibilidades para su formación profesional.

\section{Segunda constelación: De las características para ser instructor a la influencia de CONAFE en su persona}

Esta constelación se construyó con base en los criterios de selección y permanencia para ser un IC, así como por la influencia de estas dos categorías en su vida cotidiana, donde la condición de selección más importante es que se valore al joven tal como es (27 \%), seguida por su entusiasmo y su actitud emprendedora (25,5\%) y por su facilidad de adaptación e integración a la comunidad (17,5\%). En cuanto a las razones para continuar con esta labor, se encontró que la permanencia está determinada por la certeza de que al terminar tendrán el apoyo económico para seguir estudiando (65,3\%), seguida, con muy amplia distancia porcentual, por la del gusto por el trabajo con los niños (18,1\%) y por la forma en que les tratan en la comunidad (5,8\%). En cuanto a la influencia en su vida cotidiana, reconocen que el haber estado en CONAFE les ha hecho volverse personas más independientes y seguras (65,6\%) o también, el hecho de haber aprendido a ser disciplinado en los estudios (13,5\%). Como parte de las expectativas de respuesta suponíamos que los jóvenes-IC reconocerían interesarse más por lo que sucede en las comunidades donde prestan el servicio educativo, sin embargo ni siquiera uno de cada 10 lo hace, pues como hemos visto en las respuestas de la constelación anterior, el proceso de individuación en la conformación como persona autónoma está presente, por tanto, es más importante lo que les aporta la experiencia de ser IC en lo individual que en lo colectivo.

Así, encontramos que aun cuando los jóvenes-IC consideran que su participación en el programa les ayuda a ser personas más seguras e independientes, existe la tendencia a no creer que los ciudadanos puedan hacer algo en cuestiones político-sociales, pues además de que lo manifiestan abiertamente, sus acciones en el campo lo reflejan, por lo que a partir de esta constelación, se concluye que la seguridad personal y la confianza en sí mismos -que promueve el programa- no lleva necesariamente a los jóvenes-IC a la participación político-social.

\section{Tercera constelación: La influencia del CONAFE y la acción político-social}

Al revisar las características de su entorno más cercano (comunidad), vinculadas con su interés en la política y la contribución de ésta en el mejoramiento de la vida, se identificó que aun cuando no se participa en acciones concretas en el ámbito de la sociopolítica, sí existe una marcada inclinación para opinar sobre política, sobre todo en los espacios de lo privado. Esto es, más de la mitad manifiesta estar interesado en la política, pero los grados de interés varían, pues $32,4 \%$ están algo interesados mientras que 30,1\% lo está poco o $15,1 \%$ está muy interesado en contraste con $13,1 \%$ que está simplemente interesado. Lo que muestra 
polarización en la relación e involucramiento con la política, que a la par refleja la diversidad y complejidad del campo temático.

No obstante lo anterior, identificamos que 41,7 \% de los jóvenes-IC generalmente participan en la discusión y emiten su opinión cuando se está conversando de política, en menor medida $(29,7$ \%) están los que usualmente escuchan, pero no participan en la discusión y todavía son menos (14,3\%) los que simplemente en ocasiones ofrecen su opinión. Lo que tiene estrecha relación con el hecho de que a los jóvenes no se les hace tan complicada la política, esto es: $39 \%$ manifiesta que es poco complicada, además de que a $10 \%$ no le resulta nada complicada, en contraparte -nuevamente se polariza- están los que les resulta muy complicada (9,3\%) o complicada (34,7\%). A pesar de esta opinión, más de la mitad (67\%) considera que por más complicada que sea la política, es posible entenderla, aunque para algunos sí resulta realmente demasiado complicada para entenderla (24\%).

Por otro lado, nos resulta conveniente mencionar que los niveles de confianza que tienen los jóvenes hacia los ámbitos federales de gobierno y en ciertas instituciones son muy deficientes, pues la mayoría no confía en el gobierno federal $(47,5 \%)$ o se manifiesta con ambivalencia $(20,5 \%)$. A diferencia del gobierno estatal, en donde a veces se confía (40,9\%) o la mayor parte de las veces sí se confía (25,7\%). En cuanto a los niveles de confianza en las cámaras legislativas encontramos que los jóvenes no confían, pues $49 \%$ se concentra en poco o casi nada y $32 \%$ en algo para diputados, la situación empeora para los senadores, ya que $50,6 \%$ se inclinan por poco o casi nada y solo 27 \% dice que confía algo. Mención especial merece el Instituto Estatal Electoral (IEE), ya que únicamente $18,5 \%$ le tiene mucha confianza, para el resto les resulta una institución poco confiable (35\% algo, $21 \%$ poco y $10 \%$ nada). A diferencia de la Comisión Nacional de los Derechos Humanos, la cual les parece la más confiable, ya que $25,9 \%$ le otorgan mucha confianza y $38,6 \%$ algo de confianza.

Con base en los datos anteriores nos cuestionamos si, aun en un contexto de desconfianza, estos jóvenes tendrán la expectativa de expresar su voto en las elecciones próximas y si para ello cuentan con el registro necesario, a lo que la mayoría (82 \%) manifestó que sí piensa votar, un pequeño grupo dijo que no $(6,9 \%)$ y otros que aún no lo saben (6,9 \%); una cantidad mínima $(4,6 \%)$ no tuvo respuesta para esto. Si bien una cosa son los buenos deseos de participación, otra es realizar las acciones para llevarlos a cabo, no obstante, en concordancia con su deseo, la mayoría (79,9\%) de los jóvenes-IC cuentan con su credencial de elector, una minoría (3,9\%) no la tiene porque aun no está en edad para realizar el registro y el resto aún no la ha tramitado.

De acuerdo con las tendencias en esta constelación, se muestra que aun cuando no se participa en acciones concretas en el ámbito de la sociopolítica, sí existe una marcada inclinación para opinar, sobre todo en los espacios de lo privado, aunado a que los niveles de confianza que se tienen hacía los ámbitos federales de gobierno y en ciertas instituciones son muy deficientes, por lo que afirmamos que no basta con opinar, sino que es necesario ser partícipe de la acción político-social para la transformación de la sociedad.

\section{Cuarta constelación: De las condiciones y el compromiso para el ejercicio del voto al reconocimiento de la influencia de la socialización primaria en el accionar político actual}

En la constelación política reconocimos que la mayoría de los jóvenes-IC cuenta tanto con el registro en el Padrón Electoral como con la disposición para ejercer su derecho en las elecciones próximas, que gustan de opinar respecto a las cuestiones políticas cuando alguna persona 
cercana a ellos habla al respecto. Por lo que en esta constelación nos ocupamos de revisar qué tanta influencia político-participativa tuvo el joven CONAFE en su proceso de socialización primaria, para después revisar sus prácticas relacionadas con mecanismos de proselitismo político, formas de actuación en la participación política, pertenencia a algunas agrupaciones sociales, civiles y políticas y con lo que refiere al ejercicio real del voto.

En cuanto a las oportunidades que tuvieron los jóvenes-IC en su niñez para acompañar a algún familiar o conocido cercano para realizar su voto, la mayoría afirmó que sí la tuvo, es decir que: $32 \%$ algunas veces, $28,2 \%$ siempre que había elecciones y solo $9,2 \%$ pocas o raras veces. No obstante, $27 \%$ de los jóvenes-IC nunca tuvo la oportunidad de compartir esa práctica. Considerando esta práctica de socialización política, se encontró que la mayoría (79,5\%) de estos jóvenes perciben que el ejercicio del voto es la mejor forma de actuación para que los ciudadanos sean reconocidos institucionalmente en la participación política. No obstante, hubo significativa ausencia de respuesta en esta pregunta (15,1\%). Por otro lado, solo la mitad (50\%) opina que quejarse es la mejor forma para que sean tomados en cuenta y por tanto, actuar como ciudadano, además de que $23,6 \%$ de ello no ofreció respuesta.

En cuanto al proselitismo político, la mayoría $(77,2 \%)$ de los jóvenes-IC afirmaron que nunca han tenido esta práctica, $16,2 \%$ que la ha realizado de manera esporádica y solo 2,3\% lo hacen con frecuencia. Asimismo, en cuanto al ejercicio real del voto más de la mitad $(64,9 \%)$ lo pudo llevar a cabo, $24,7 \%$ no lo realizó y $10,4 \%$ no contaba con la edad para hacerlo, comportamiento que se asemeja a la media nacional.

Finalmente, se analizó si tenían alguna adscripción a una organización social al momento que se aplicó la encuesta, a lo que más de la cuarta parte (34,7\%) mencionó que a ninguna, el $19,3 \%$ a agrupaciones estudiantiles, $15,8 \%$ grupos deportivos y solo $12 \%$ a las de servicio a la comunidad.

A partir de los resultados presentados, se identificó que los espacios y mecanismos reales de participación y adscripción sociopolítica de estos jóvenes es escasa, debido a que se encuentran en un proceso de conformación identitaria, en el que resulta de mayor importancia su formación personal y los capitales que les permitan la movilidad social, más que el accionar político-social en concreto. No obstante y con base en la información arrojada en las entrevistas, la valoración de la experiencia de haber participado en un espacio alternativo de formación, se da a posteriori, ya que su participación en el campo sociopolítico se da tiempo después de haber participado en el programa, es decir, se reconoce mejor en la distancia, como se pudo apreciar en las historias de vida (Molina, 2008).

\section{Conclusiones}

Si consideramos que las identidades son fuente de sentido para los propios actores y son construidas mediante la experiencia social (Dubet, 2010, 2011), éstas pueden dar como resultado prácticas normalizadoras o de subjetivación. De acuerdo con este autor, al plantear que la experiencia social se construye a partir de la interacción de distintas lógicas (de integración, de estrategia y de subjetivación), podemos decir que cuando los jóvenes-IC están en un proceso de construcción de su individualidad, valoran su crecimiento personal por encima del trabajo comunitario, por tanto, estarían asumiendo más una identidad legitimadora (Castells, 2004), que solo cumple con el rol (identidad integradora) donde predomina una perspectiva de vida que apunta a una condición nautonómica y por ende, asume relaciones heterónomas, 
debido a que para algunos jóvenes-IC es más importante su formación personal y los capitales que le permitan la movilidad social, más que el accionar político-social en concreto, lo cual genera pocas posibilidades de participación en la reconfiguración de sus perspectivas de vida.

También se pudieron identificar indicios de resistencia del individuo a las imposiciones, con posibilidades de asumir una perspectiva autonómica; sin embargo, ésta no logra concretase, porque consideran que son más determinantes las condiciones estructurales de la sociedad. Lo que nos lleva a afirmar que se quedan en un punto de transición entre una identidad legitimadora y una identidad de resistencia. Pues si bien admiten que el CONAFE les ayuda a ser personas seguras e independientes, existe la tendencia a creer que esto no es suficiente para que puedan participar en el cambio político y social del país, condición que los llevaría a transitar de identidad de resistencia a una identidad proyecto.

Finalmente, concluimos que las instituciones alternativas de formación pueden constituir espacios para la construcción de experiencias que favorezcan la participación activa de los sujetos en los distintos ámbitos de la vida social. En el caso particular del campo sociopolítico, tal participación se puede dar cuando los actores redefinen su posición social y buscan transformar la estructura social, asumiendo una identidad proyecto, que requiere construir espacios de subjetivación, es decir, el deseo del sujeto de ser autor o actor que se define por lo que hace, por lo que valora y por las relaciones en que se encuentra comprometido.

\section{Referencias bibliográficas}

Almond, G. y Verba, S. (1963). The Civic Culture: Political attitudes and democracy in five Nations. Princeton: University Press.

Alpizar, L. y Bernal M. (2003). La construcción social de las juventudes. Revista Última Década, No 19 , pp. 105-123.

Beck, U. (1999). Hijos de la Libertad. México: FCE.

Bourdieu, P. (1984). Sociología y Cultura. México: Grijalbo-Los Noventa.

Castells, M. (2004). La era de la información. El poder de la identidad. (Vol. II.) México: Siglo XXI.

Castro, P. (2011). Cultura política: una propuesta socio-antropológica de la construcción de sentido en la política, en Región y Sociedad, vol. XXIII, núm. 50, enero-abril, 2011, pp. 215247.

Dietz, G. Mendoza y Téllez S. (Eds.) (2007). Multiculturalismo, Educación Intercultural y Derechos Indígenas en las Américas. Quito, Ecuador: Abya-Yala.

Dubet, F. (2010). Sociología de la experiencia. Barcelona: Complutense-CIS.

Dubet, F. (2011). La experiencia sociológica. Barcelona: Gedisa.

Durand, V. M. (1998). La cultura política de los alumnos de la UNAM. México: Miguel Ángel Porrúa.

Erikson, E. (1986). Identidad: juventud y crisis. Madrid: Taurus.

García Salord S. y Vanella, L. (1992). Normas y valores en el salón de clases. México: Siglo XXI/UNAM.

Gómez Nashiki, A. (2003). El movimiento estudiantil mexicano. Notas históricas de las organizaciones políticas, 1910-1971. Revista Mexicana de Investigación Educativa, vol. 8, núm. 17, enero-abril, pp. 187-220. 
Gutiérrez, R. (1996). La Cultura política en México: teoría y análisis desde la Sociología. En Krotz, E. (Coord.) El Estudio de la cultura política en México. Perspectivas disciplinarias y actores políticos. México: CONACULTA-CIESAS.

Held, D. (1997). La democracia y el orden global. Del Estado moderno al gobierno cosmopolita. Buenos Aires: Paidós.

IMJ (2002). Jóvenes Mexicanos del siglo XXI. Encuesta Nacional de Juventud 2000. México: IMJ.

IMJUVE (2015). Políticas de operación. Generación y articulación de políticas públicas integrales de juventud. México: SEDESOL.

Inglehart, R. (1997). Modernization and Postmodernization. Cultural, Economic and Political Change in 43 Societies, Princeton: University Press.

Krotz, E. (Coord.) (1996). El Estudio de la cultura política en México. Perspectivas disciplinarías y actores políticos. México: Consejo Nacional para la Cultura y las Artes, Centro de Investigaciones y Estudios Superiores en Antropología Social.

Krotz, E. (2002). La investigación sobre la cultura política en México: visión panorámica de un campo de estudio en construcción. En Winocur, R. (Coord.) Algunos enfoques metodológicos para estudiar la cultura política en México. México: Porrúa, IFE, FLACSO.

López, L. E. (Ed.) (2009). Interculturalidad, educación y ciudadanía: Perspectivas latinoamericanas. La Paz, Bolivia: FUNPROEIB Andes, Plural Editores.

López de la Roche, F. (2000). Aproximaciones al concepto de la Cultura Política, en Convergencia $N^{\circ} 22$, pp. 93-123.

Maffesoli, M. (1990). El tiempo de las tribus. El declive del individualismo en las sociedades de masa. Barcelona: Icaria.

Mannheim, K. (2004). Ideología y utopía: Introducción a la Sociología del Conocimiento. México: FCE.

Martín, J. (2001). Tecnicidades, identidades, alteridades: des-ubicaciones y opacidades de la comunicación en el nuevo siglo, en revista Diálogos, No. 64, pp. 9-24.

Meyerberg, Y. (1997). Modelos de política, percepciones políticas, gestión gubernamental. En Beltrán, Castaños, Flores, Meyenberg y Del Pozo (Comps.). Los mexicanos de los noventa. México: IIS, UNAM.

Molina, A. (2000). Estudio etnográfico sobre formación de valores para la democracia en el sexto grado de primaria en ocho escuelas de la ciudad de México y su área metropolitana. México: Universidad Iberoamericana. Tesis Maestría en Investigación y Desarrollo de la Educación.

Molina, A. (2008). Constelaciones de Cultura Política Juvenil: El caso de los Instructores Comunitarios de Conafe-Hidalgo. Pachuca, Hidalgo/UAEH. Tesis. Doctorado en Ciencias de la Educación.

Molina, A. y Ponce, C. (2011). Juventud y cultura política. Matices del Posgrado Aragón, No. 14, pp. 133-149.

Molina, A. (2011). Prácticas y espacios para la formación ciudadana: una revisión desde el programa de Formación Cívica y Ética en educación secundaria. México: UAEH.

Molina, A. y Heredia E. (2013). Educación y valores en el ámbito de la formación ciudadana y los derechos humanos, en Yurén T. y Hirsch A. (Coord. Gral.) La investigación en México en el campo Educación y Valores. 2002-2011. (cap. 4 pp. 211-272). México: ANUIES/COMIE.

Monsiváis, A. (2004). Vislumbrar la ciudadanía: jóvenes y cultura política en la frontera noroeste de México. Tijuana: El Colegio de la Frontera Norte y Plaza y Valdés. 
Parsons, T. (1984). El sistema social. Madrid: Alianza Editorial.

Pérez Islas, J. A. (Coord. Gral.) (2006). Encuesta Nacional de Juventud 2005, México, Instituto Mexicano de la Juventud, Centro de Investigación y Estudios sobre Juventud (Memoria Digital).

Pérez Islas, J. A. (2010). La discriminación sobre jóvenes. Un proceso de construcción. El Cotidiano, núm. 163, septiembre-octubre, pp. 35-44.

Reguillo, R. (2000). Las culturas juveniles: un campo de estudio, Breve agenda para la discusión. En Medina, G. (Comp.) Aproximación a la diversidad juvenil. México: EL COLMEX.

Reguillo, R. (2002). Jóvenes y esfera pública. Documento teórico y análisis de resultados, en Pérez Islas, J. A. (Coord. Gral.) Jóvenes Mexicanos del Siglo XXI. Encuesta Nacional de Juventud 2000, México: Instituto Mexicano de la Juventud.

Reguillo, R. (2010). Condición juvenil en el México contemporáneo. En Reguillo, R. Los jóvenes en México. México: FCE/Conaculta (pp. 395-429).

Rodríguez Kauth, A. (2001). La Psicología Social y La Psicología Política Latinoamericana: Ayer y hoy. Psicología Política, № 22, mayo. pp. 41-52.

Rodríguez McKeon, L. (2009). La configuración de la formación de ciudadanía en la escuela. Análisis de un caso en educación secundaria. México: Universidad Pedagógica Nacional.

Rodríguez Mckeon, L. y Elizondo, A. (2010). La innovación en la formación cívica y ética. Dilemas tensiones y paradojas del cambio curricular en la escuela primaria. México: UPN. Colección Horizontes educativos.

Salinas, B. (2003). Educación, ciudadanía, organización y comunidad. En Bertely, M. (Coord.) Educación, Derechos Sociales y Equidad, Tomo II, COMIE, México. (Capítulo 3, pp. 683-711).

Sarramona, J. (1993). Cómo entender la democracia en la escuela. Barcelona: CEAC.

Schmelkes, S. (1997). La escuela y la formación valoral autónoma, México: Castellanos Editores.

Schneider, C. y Avenburg, K. (2015). Cultura Política: Un Concepto Atravesado por dos Enfoques. POSTData 20, № 1, abril-septiembre, pp. 109-131.

Segovia, R. (1975). Politización del niño mexicano, México: El Colegio de México.

Taguenca J.A. (2009). El concepto de Juventud. Revista Mexicana de Sociología 71, núm. 1, eneromarzo. pp. 159-190.

Tapia, M., Barba L., Elizondo A., y Fernández C. (2003). Formación cívica en México: 1990-2001. En Bertely, M. (Coord.) Educación, Derechos Sociales y Equidad, Tomo III, COMIE, México. (Capítulo 4, pp. 987-1005).

Trejo, J. A., Arzate, J. e Itati, A. (Coords.) (2010). Desigualdades sociales y ciudadanía desde las culturas juveniles en América Latina. México: UAEM/Porrúa.

Urteaga, M. (2012). La construcción juvenil de la realidad. Jóvenes mexicanos contemporáneos. Innovación Educativa, vol. 12, número 60, septiembre-diciembre, pp. 159-163.

Yurén, T. (1995). Eticidad, valores sociales y educación. México: Colección de Textos Nº 1, UPN.

Yurén, T. (2013). Ciudadanía y Educación. Ideales, dilemas y posibilidades de la formación éticopolítica. México: Juan Pablos/UAEM.

Yurén, T. (2014). El desarrollo de las capacidades para una vida democrática vigorosa. EDETANIA 46, diciembre 2014, pp. 105-121. 